\title{
Structure of emergency automatics in UPS of Russian Federation
}

\author{
Lev Koshcheev ${ }^{1}$, Andrei Lisitsyn ${ }^{1}$, and Evgeniy Popkov ${ }^{2, *}$ \\ ${ }^{1}$ JSC «STC UPS», Kurchatov St. 1, lit A, St. Petersburg, 194223, Russian Federation \\ ${ }^{2}$ Peter the Great St. Petersburg Polytechnic University, Polytechnicheskaya 29, St. Petersburg, \\ 195251, Russian Federation
}

\begin{abstract}
There are emergency automatics systems (EA) widely used in Unified Power System (UPS) of Russian Federation. Main focus of article is centered on design principles of preventive automatics for stability control schemes (PASCS) as this automatics is the most complex type of EA. Features of PASCS are determined by modern state-of-the-art of digital technique and information technology, that decide the innovative developmental character of PASCS. Information about development and implementation of centralized emergency automation systems (CEAS) in power systems of Russian Federation is also given here.
\end{abstract}

\section{Introduction}

Emergency automatics system is widely applied in Unified Power System (UPS) of Russian Federation. This EA system is intended to on-time detection of emergency disturbances and to prevent the evolution and to eliminate danger emergency modes in power system [1-7].

Following types of EA are applied in Russian UPS:

- preventive automatics for stability control schemes (for static and transient stability of generation equipment parallel operation) (PASCS) in case of appearance of short circuits, emergency shutdown of network and generation equipment, overload by active power in monitored sections of power grid;

- automatics for elimination of asynchronous operation (AEAO) for separate generators, power plants and parts of power systems;

- automatics for limitation of frequency deviation (automatics for limitation of frequency increasing (ALFI) and automatics for limitation of frequency decreasing (ALFD)) intended to prevent inadmissible frequency deviation by value and duration in case of considerable emergency unbalances of active power in power system;

- $\quad$ automatics for limitation of emergency voltage deviation (automatic overvoltage protection (OP) and undervoltage protection - automatics for limitation of voltage decreasing (ALVD)) intended to prevent inadmissible voltage deviation by value and duration);

\footnotetext{
* Corresponding author: enpopkov@gmail.com
} 
- $\quad$ preventive automatics of equipment overload (PAEO) - by value and duration for load current of network equipment.

Secure and effective operation of power system EA is assured by means of application of centralized and decentralized emergency control, implementation of hardware and functional redundancy principles, independent operation of each above EA subsystem. Such approach of EA designation allows to ensure: effective emergency control including appearance of non-standard emergency disturbances, considerable restriction of the emergency modes distribution in power system, minimum time to eliminate these emergency mode and normal operation recovery in power system.

\section{Methods (algorithms) of emergency control systems}

Preventive automatics for stability control schemes (PASCS) of power system is the most complex and innovative type of emergency automatics based on research assessment exercises, knowledge of static and dynamic (transient) characteristics of power system, present-day developments in the field of digital technique and information technology.

PASCS is the combination of EA devices, that are intended to prevent violation of static and transient stability during standard emergency disturbances (hereinafter - standard disturbances) and to ensure the margin of static stability for given power system sections in post-fault conditions.

PASCS is the first line of emergency automatics system in power system. Standard disturbances that are specified by standard and technical documentation and considered during power system PASCS engineering are the following [8]:

- tripping of grid objects $110-750 \mathrm{kV}$ by RPA operation in the case of short circuits with consequent successful/unsuccessful autoreclosing (for different types of short circuits);

- tripping of grid objects $110-750 \mathrm{kV}$ in the case of short circuits (for different types of short circuits) with the fact of circuit breaker failure and consequent operation of breaker failure protection;

- $\quad$ tripping of busbar $110-750 \mathrm{kV}$;

- $\quad$ appearance of active power imbalance as a result of generation equipment or large consumers shutdown.

Above mentioned standard disturbances are considered both in normal and maintenance grid layout.

If in any reason PASCS will not operate effectively and the stability loss nevertheless occurred, then AEAO subsystem will ensure the elimination of asynchronous operation of power system by means of re-synchronization of power system or division of power grid. Other EA subsystems provide emergency control using electrical parameters of emergency mode obtained from different power system nodes. This control normalizes values if frequency, voltage, load of power grid objects, power flows to its acceptable ranges.

PASCS of power system is engineered as centralized emergency automatics system (CEAS), providing ability of operation both in centralized and decentralized modes. System is created according to hierarchic principle and includes two levels of hierarchy control (figure 1):

- $\quad$ level of consolidated (CPS) or regional power system - upper level of CEAS;

- level of power object - local preventive automatics for stability control schemes (LPASCS) - lower level of CEAS. 


\section{EECE-2018}

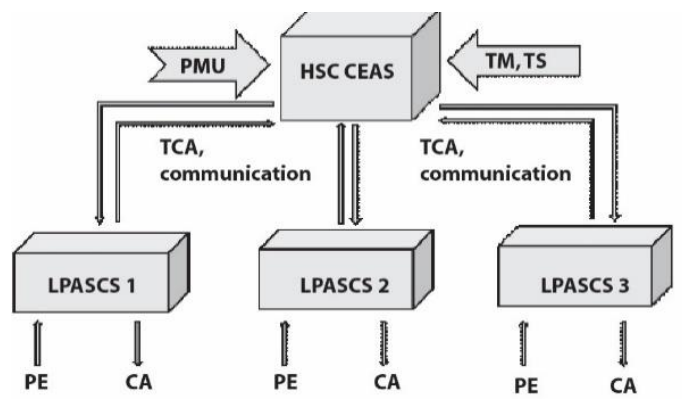

Fig. 1. CEAS structure

Hardware and software complexes of upper level of CEAS (HSC CEAS) are installed in System Operator dispatching centers. HSC CEAS use the following real time data: layout and mode conditions of power system; available scope of control actions (CA) from operative-information complex (OIC) of automated systems of dispatch control $[9,10]$. HSC CEAS performs cyclic evaluation of power system condition using power system mathematical model, calculates steady-state and transient electrical modes and generates tables of control actions (TCA) that are include for given pickup elements the correlation between pickup elements (PE), type, scope and location of appliance of CA (figure 2).

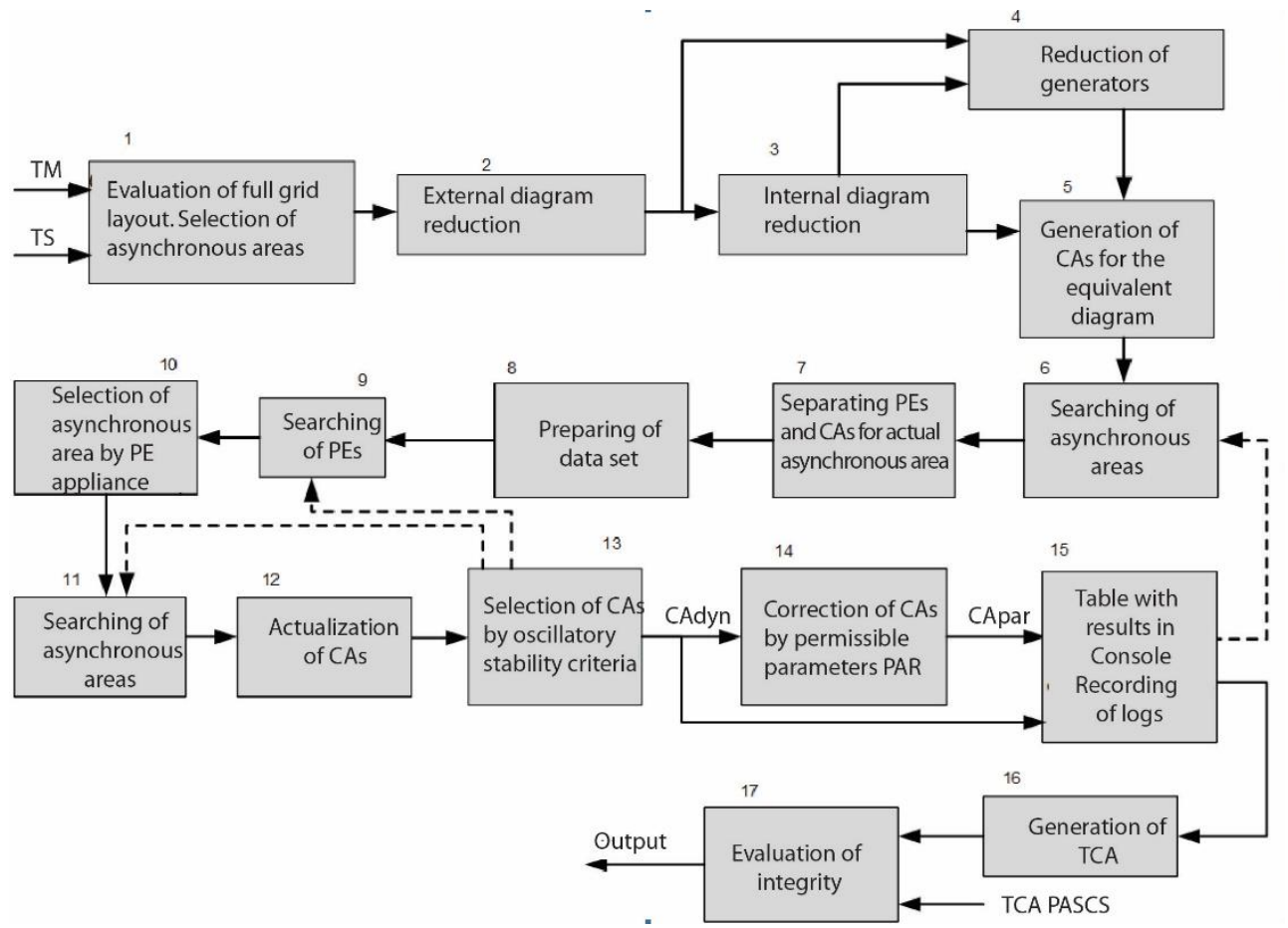

Fig. 2. General functional scheme of technological algorithm of CEAS

TCA is the instruction for parameterization of lower level LPASCS devices. Updated TCAs for actual layout and mode conditions are transferred from upper level of CEAS to LPASCS after completion of calculation cycle to apply CA when receiving the appropriate signal from PE. 


\section{Results (the use of emergency control systems in Russian UPS)}

Parameters of calculation models, the number of PEs and CAs of CEAS placed into operation in Russian UPS, are listed in table 1.

Table 1. CEAS characteristics

\begin{tabular}{|l|c|c|c|c|c|}
\hline \multirow{2}{*}{\multicolumn{1}{|c|}{ CEAS }} & \multicolumn{2}{|c|}{ Parameters of calculation model } & \multicolumn{2}{c|}{ Number } \\
\cline { 2 - 6 } & Nodes & Branches & Generators & PE & CA \\
\hline CPS of East Region & 746 & 1022 & 75 & 68 & 14 \\
\hline CPS of North-West Region & 1429 & 2001 & 208 & 12 & 27 \\
\hline CPS of Siberia & 367 & 588 & 98 & 37 & 23 \\
\hline CPS of mid-Volga Region & 209 & 416 & 190 & 63 & 37 \\
\hline Power system of Tyumen & 110 & 235 & 60 & 132 & 94 \\
\hline CPS of Ural & 149 & 263 & 119 & 113 & 43 \\
\hline CPS of South Region & 499 & 931 & 170 & 45 & 64 \\
\hline
\end{tabular}

First CEAS was developed by Russian experts and put into commercial operation at CPS of Ural Region in 1986. Originator and coordinator of development of CEAS technology in Russian Federation is System Operator. Taking into account that development of CEAS for each power system is exclusive process, one can state that updating procedure of CEAS is continuous. At the present time CEAS of third generation is under implementation in Russian UPS.

CEAS of third generation was developed and put into operation at CPS of East Region in 2014 [11].

\section{Discussion}

Development of CEAS functional capabilities is specified by necessary of processing of huge data sets at real time base and limited by state-of-the-art of information technology required for high-speed machine-to-machine communication, acquisition of data about layout and mode condition in power systems and calculations. State-of-the-art level of computing technology allows to simplify essentially the problems of development of CEAS technological software due to namely limited abilities of computing technology, that required in due time to develop unique engineering reduction methods and calculation models of power system. Exclusiveness of these models caused large problems during their application: changing of power system layout required the correction of calculation models.

Above mentioned problems are solved in modern version of CEAS. It is possible due to implementation of multiagent principles of control of computing system resources, solved problem of paralleling calculation, increasing of dimension of calculation models to maintain the static and transient stability, implementation of classic methods of stability calculation and CA selection in technological algorithms. These facts allow to increase essentially efficiency, adaptivity and reliability of automatic post-fault control and simultaneously keep the normalized value of calculation cycle duration of $30 \mathrm{~s}$, fix the above problems concerning application, correction and verification of calculation models in case of changing of power system operation conditions.

To prevent the loss of stability the following types of CAs applied:

- $\quad$ shutdown of generation equipment on power plants (SG);

- $\quad$ load shedding of power consumers (LS);

- $\quad$ short-term (impulse) (SLS) and long-term load shedding (LLS) of power units at HPP and NPP; 
- $\quad$ automatic upload of generation equipment of power plants (AUG);

- $\quad$ electrical breaking (EB);

- changing of power grid topology;

- $\quad$ changing of operation mode of controlled grid objects.

SG is applied to prevent the loss of stability of generation equipment, limitation of frequency increasing, elimination of overload of monitored grid sections, transmission lines and equipment. SG is performed by tripping of generator out of the grid with its simultaneous connection to the auxiliaries or switching to the no-load conditions for its following fast reconnection to the grid.

LS is applied to prevent the loss of stability, limitation of frequency and voltage decreasing, elimination of overload of monitored grid sections, transmission lines and equipment. LS is performed by tripping of all electrical links of power consumers load installations with inhibition of autoreclosing and automatic transfer scheme for tripped feeders.

SLS is applied to prevent loss of transient stability of generation equipment at power plants. LLS is applied to prevent loss of static stability, elimination of overload of monitored sections, power transmission lines and equipment. Technical characteristics of SLS and LLS are defined during full-scale tests of regulations systems of power units. SLS and LLS are provided at all of power units at TPP and NPP with rated power of $500 \mathrm{MW}$ and higher. SLS together with LLS allow to ensure effective emergency control without shutdown of generation equipment (SG) or to reduce essentially the value of SG.

AUG is applied to recover the power system frequency, elimination of overload of monitored sections, power transmission lines and equipment.

EB of generators is applied to prevent loss of transient stability of generation equipment at power plants. EB is performed as short-term automatic connection of active load resistances to synchronous generators' busbar.

Changing of power system topology is used to eliminate equipment overload and to limit voltage decreasing and increasing. Changing of power system topology is performed by tripping of power grid equipment that do not operate to divide the grid.

Changing of operation mode of controlled grid objects are applied to prevent loss of stability, to eliminate of overload of monitored sections, power transmission lines and equipment and also to limit frequency decreasing.

Within this project the following tasks were completed:

1. Development of calculation algorithm and software (SW) for selection of control actions to keeping static stability using standard calculation methods.

2. Development of calculation algorithm and SW for selection of control actions to keeping stability at active stage of transient process.

3. Development of new algorithm and SW for evaluation of actual electrical condition of power system.

4. Development of modern architecture of HSC for upper level of CEAS:

- new technologies of development and implementation of technological SW;

- new database structure;

- multiserver and multiple processor system of parallel computations;

- upgraded control system of HSC computational capabilities.

5. Assurance of maximum flexibility (CEAS can operate in power systems of any layout and configuration).

6. Increasing of CEAS operation speed by means of transition to parallel calculation of pickup elements.

7. Increasing of operation reliability of CEAS.

At the present day development of CEAS technology is assured by: designing and implementation of CEAS of third generation at all CPSs of Russian Federation and separate 
large regional power systems; using of synchrophasor data of electrical mode of power system to evaluate condition of PEs and to develop the new ones; implementation of stateof-the-art information technology; realization of algorithms of coordinated emergency control allowing cooperation of CEAS of adjacent areas to correct each other.

\section{Conclusions}

Extensive application of CEAS in Russian UPS allows to prevent severe system accidents with continuous outage of power consumer supply in case of appearance of emergency disturbances even in off-nominal repair layouts of power system. It is possible due to cyclic real-time selection of minimum and the most effective CAs for given emergency disturbances and actual layout and mode conditions.

Application of CEAS optimizes the scope of emergency control and increases transmission capability of power grid keeping required reliability level. Developed technological algorithms of CEAS are applied in systems that monitor margin of stability at monitored sections of power grid. Further development of CEAS one can expect as advancement of software and hardware platform that will increase system reliability and vitality, development of lower level devices and receipt-transmission devices infrastructure, creation of dynamic multiagent models.

\section{References}

1. N.A. Belyaev, N. V. Korovkin, V.S. Chudny, and O. V Frolov, in 2015 IEEE Eindhoven PowerTech, PowerTech (Institute of Electrical and Electronics Engineers Inc., 2015), p. 7232323 (2015)

2. N.A. Belyaev, N. V Korovkin, V.S. Chudny, and O. V Frolov, in Proc. 2015 IEEE North West Russ. Sect. Young Res. Electr. Electron. Eng. Conf. ElConRusNW 7102251, 150-154 (2015)

3. P. V Chernyaev, V.S. Chudny, and S. V. Smolovik, in Proc. 2016 IEEE North West Russ. Sect. Young Res. Electr. Electron. Eng. Conf. EIConRusNW 20167448239, 530-533 (2016)

4. A.S. Brilinskii, G.A. Evdokunin, R.I. Mingazov, N.N. Petrov, and V.S. Chudnyi, Power Technol. Eng. 51(5), 584-592 (2018)

5. E.B. Sheskin and G.A. Evdokunin, Power Technol. Eng. 50, 108 (2016).

6. S. V Smolovik, A.S. Liamov, V. V Teplukhin, A.L. Tupitsina, and V.S. Chudny, in Proc. 2018 IEEE Conf. Russ. Young Res. Electr. Electron. Eng. ElConRus 2018, 784788 (2018)

7. N. Silin, N. Korovkin, and T. Minevich, in 2017 Int. Conf. Ind. Eng. Appl. Manuf. ICIEAM 2017, 8076412 (2017)

8. Methodical Guidelines for Power Systems Stability, as approved by order of RF Ministry of Energy from 30.06.2003 № 277 (2003)

9. A. Lisitsyn, P. Katz, A. Zhukov, E. Satsuk, Collected lectures of 4th international scientific and technical conference "Modern trends of relay protection and automation of power systems", Yekaterinburg, Russia, 03-07 June (2013)

10. S. Pavlushko, A. Zhukov, E. Satsuk, P. Katz, A. Lisitsyn, Power Plants, 1, 151-156 (2015)

11. P. Kats, L. Koshcheev, A. Lisitsyn, M. Edlin, A. Zhukov, P. Legkokonets, E. Satsuk, CIGRE Session 45, Paris, 24-29 August (2014) 